http://jmscr.igmpublication.org/home/ ISSN (e)-2347-176x ISSN (p) 2455-0450

crossref DOI: https://dx.doi.org/10.18535/jmscr/v7i12.84

\author{
Journal Of Medical Science And Clinical Research \\ IGM Publication \\ An Official Publication of IGM Publication
}

\title{
A fixed fixed partial denture for a pier abutment
}

\author{
Authors \\ Kavita Raj ${ }^{*}$, Manvi Singh ${ }^{2}$ \\ ${ }^{1}$ Lecturer, Department of Prosthodontics, Chandra Dental College, RMLA University \\ ${ }^{2}$ Postgraduate student, Department of Prosthodontics, Chandra Dental College, RMLA University \\ *Corresponding Author
}

Kavita Raj

Abstract
The life of a fixed partial denture depends largely on how well the partial denture is able to maintain the
health of the periodontium. Periodontal breakdown of any sort due to a prosthesis means the failure of the
restoration. This is applicable to a normal and healthy abutment. Some situations like pier abutment
require special attention and understanding of the biomechanics of occlusion. We present a clinical case of
a female patient who had a pier abutment situation in the mandibular arch. A fixed fixed partial denture
was cemented in place since the patient was not able to afford the cost of a precision attachment that was
necessary to fabricate a fixed movable bridge for such case. The patient reported to be satisfied after one
year follow up.
Keywords:abutment, lever, decementation, precision attachment, long span bridge.

\section{Introduction}

A healthy abutment may not necessarily be a right abutment to support a fixed partial denture. Such example is seen when an abutment tooth is surrounded on either side by an edentulous area. The situation of the abutment is also called as a pier abutment. In such cases, the use of a fixed fixed partial denture has not been advised since occlusal forces cause cementation failure either of the anterior abutment or of the posterior abutment depending upon the area where the forces are excessive. ${ }^{1}$ The retainer on the pier abutment acts as a fulcrum which can cause failure of the weaker retainer within a bridge.The use of non rigid connectors in such cases allows the stress to be broken, thus preventing the debonding failure. ${ }^{2}$ Since the non-rigid connector allows certain movements within the two component fixed partial denture, the debonding of such restorations is rarely seen. However, it has also been stated that when a premolar is used as an abutment, there is no evidence that premolar acted as a fulcrum. ${ }^{3}$ Another problem with the use of a non-rigid connector is its availability, cost and technique sensitivity since incorporation of a precision attachment within a cast bridge that shrinks on cooling impairs fitting of the two components of precision attachment. ${ }^{4,5}$

We present a case of a mandibular pier abutment that was restored successfully by a rigid connector rather than a non rigid connector.

\section{Case Report}

A female patient was referred to the outpatient department of the department of prosthodontics with chief complaint of inability to masticate the food due to absence of mandibular teeth. Medical and social histories were irrelevant to her existing condition. The patient had got her mandibular left 
first premolar and first molar extracted due to caries about 8 months ago. The patient had an anterior spacing with a class 1 molar and canine relations. A thorough history, clinical and radiographic examination was done after procuring a mounted diagnostic cast and various treatment options were presented to the patient. The first choice was an implant supported two individual crowns while the second option was a fixed, movable bridge with fixed fixed bridge being the last option. Due to financial limitations of the patient the last option of a fixed fixed bridge was consented by her. The treatment began and ended with routing clinical and laboratory procedures for fixed partial denture treatment. The entire bridge was designed with occlusal surfaces in metal and porcelain facing on the buccal sides except the last molar (Fig 1A, B). The fixed partial denture was cemented with zinc phosphate cement (Harvard) and the patient was given instructions regarding oral hygiene maintenance (Fig 2A, B). The patient was educated about possible complications related to the design of the fixed partial denture. The patient was put on a regular follow up for a period of 6 months (monthly) followed by a period of three month intervals. The patient did not report any complication at one year follow up visit and there was no sign of any cementation failure of any retainer (Fig 2C).

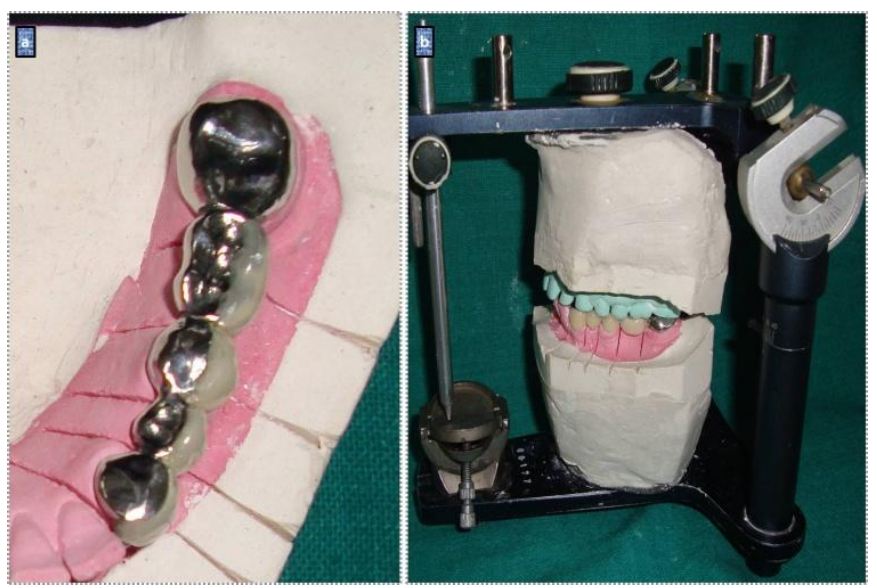

Figure 1: (A) Various designs of individual retainer and pontics $(B)$ The bridge in occlusion

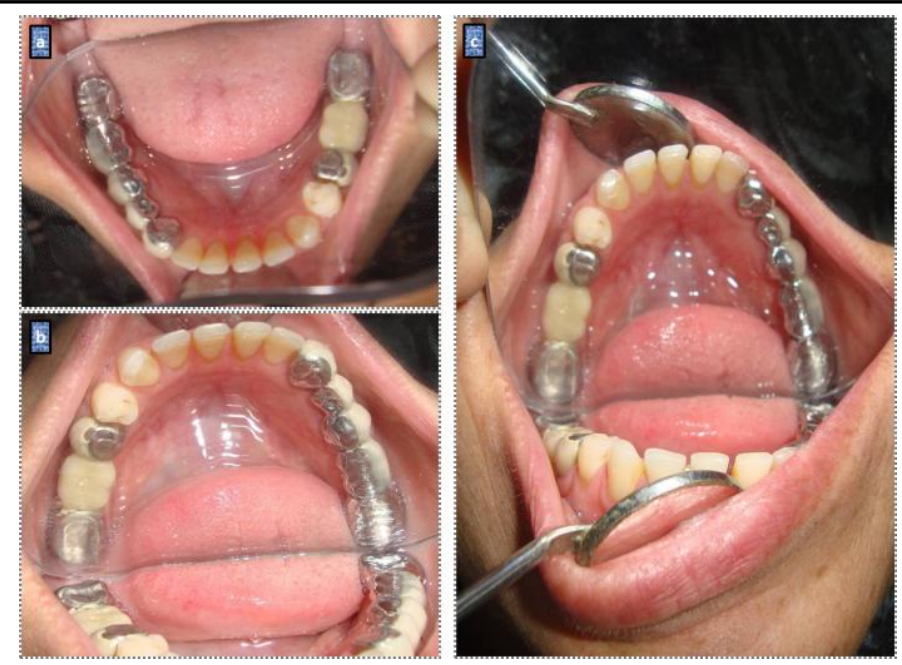

Figure 2:(A and B) Intra oral view of cemented fixed fixed bridge (B) Follow up at one year

\section{Discussion}

Selection of abutment for supporting a fixed or a removable partial denture is primarily done on the anatomy of the tooth, its size, shape, root configuration while little has been written about the role of occlusion on selection of abutments. In a pier abutment situation, it has been said that when a fixed fixed bridge is given there is a tendency that the terminal abutments will intrude during function and this results in teetering movement thus causing the failure of a weaker retainer. ${ }^{1,6}$ to overcome such failures, the use of non-rigid connectors has been advocated which fall into the category of precision and semi precision attachments. The use of precision attachments is a highly technique sensitive procedure since the accuracy of casting is primary for the final fit of the matrix and patrix components of the precision attachment. Casting shrinkage that is inherent to base metal alloy castings should be compensated accurately to ensure that the two components fit clinically. Unfortunately, in this part of the world we lack laboratory technicians and the availability of affordable precision attachments which is why they are not used much by practicing dentists.

The case we presented had two important favouring factors for provision of a fixed fixed partial denture. These were the built of the patient (thin and lean), non-vegetarian diet and opposing cuspless occlusion. When combined together, the chances of 
excessive forces generated during mastication were predicted to be minimal which led to the decision of giving a fixed fixed bridge rather than a fixed movable bridge. The only apprehension regarding long term success of the fixed fixed bridge was the presence of supraeruption of maxillary posterior tooth which was corrected according to the principles mentioned in the literature. ${ }^{8}$ another treatment option that was considered was the use of a cantilever bridge but due to the presence of supraerupted opposing tooth, the feasibility of cantilever bridge was not considered. ${ }^{9}$ The use of metal occlusal was chosen with the intention of providing a favourable occlusal surface that minimizes clinical adjustments during trial and cementation procedures. Although the patient being a female subject, who was concerned about the esthetic value of porcelain, her subjective apprehensions were overcome with proper patient education about functional aesthetics. ${ }^{10}$

\section{Conclusion}

Although there is enough literature favourable the use of fixed movable bridge for management of a pier abutment, there is little evidence that fixed fixed bridges fail in such cases. At the same time, patients where occlusal forces are anticipated to be less, the use of fixed fixed bridge as a treatment option should not be ruled out.

\section{Acknowledgements}

The authors would like to acknowledge the effort of other staff of the department whose opinion was invaluable at difficult times.

\section{References}

1. Markley K. Broken-Stress. Principle \& design in fixed bridge prosthesis. JPD 1951;1:416-23.

2. Shillingburg HT,Fisher DW. Non-rigid connectors for fixed partial dentures. J Am Dent Assoc1973;87:1195-99.

3. Standlee JP, Caputo AA. Load transfer by fixed partial denture with three abutments. Quintessence Int 1988;19:403-10.
4. Mattoo KA, Jain S. Managing a case of sensitive abutment situations through use of a Fixed Movable Prosthesis. J Med Sci Clin Res 2014;2:1858-63

5. Gaba N, Mattoo KA. Converting a removable prosthetic option into fixed by using custom made non-rigid connector. WebmedCentral DENTISTRY 2014;5:17:WMC004695

6. Oruc S, Eraslan O, Tukay HA, Atay A. Stress analysis of effect of non rigid connectors on fixed partial dentures with pier abutments.J Prosthet Dent 2008;99:18592.

7. Mattoo KA, Brar A, Goswami R.Elucidating the problem of pier abutment through the use of a fixed movable prosthesis - A Clinical case report. International Journal of Dental Sciences and Research 2014;2:15457

8. Darraj A, Mattoo KA.Full Mouth Rehabilitation Involving Occlusal Plane Correction. Journal of Medical Sciences and Clinical Research 2017;5:28204-208

9. Rahman S, Mattoo KA. Partial veneer retained fixed partial denture in conjunction with cantilevered bridge to fulfill the objective of patient perceived aesthetics. Ann Int Med Dent Res 2017;3;32-35

10. Al Moaleem MM, Alkhayrat FM, Madkhali HA, Geathy IH, Qahhar MA, Yaqoub A and Mattoo KA.Subjective differences between dentists and patients about relative quality of metal ceramic restorations placed in the Esthetic Zone.J Contemp Dent Pract 2017;18:112-116. 